\title{
Peeled volume models of a whole body to enhance comprehension of anthropological bone landmarks
}

\author{
K. Kwon'1, M.S. Chung ${ }^{2}$, B.-S. Shin ${ }^{3}$, B.S. Chung ${ }^{2}$ \\ 'Department of Smart Information Technology, Baewha Woman's University, Seoul, Republic of Korea \\ 2Department of Anatomy, Ajou University School of Medicine, Suwon, Republic of Korea \\ ${ }^{3}$ Department of Computer Engineering, Inha University, Incheon, Republic of Korea
}

[Received: 12 February 2019; Accepted: 22 February 2019]

\begin{abstract}
Background: In physical anthropology, bone landmarks are palpated in living humans for the identification of corresponding skin landmarks and exact biometry. The purpose of this study is to help comprehend the locations and depths of representative bone landmarks all over the body.

Materials and methods: The sectioned images of a male cadaver's whole body were used to build a volume model, which was continuously peeled at $1 \mathrm{~mm}$ thicknesses to disclose 27 selected landmarks in the anterior, lateral, or posterior views. Results: The captured views of peeled volume models along with the labels of the bone landmarks were loaded to browsing software that was distributed for free. The browsing software containing the peeled volume models will enhance convenient studying of the bone landmarks.

Conclusions: With the knowledge of bone landmarks, investigators would be able to attain more accurate measurements between skin landmarks. (Folia Morphol 2019; 78, 4: 833-838)
\end{abstract}

Key words: visible human projects, cadaver, three-dimensional imaging, bone, anatomic landmarks

\section{INTRODUCTION}

Bone landmarks on excavated bones are identified for forensic medicine $[5,19]$ and archaeological anthropology. Bone landmarks not only in dry bones but also in living humans are identified for physical anthropology [17] and clinics. It is because the bone landmarks correspond to skin landmarks (e.g., glabellare and glabella) which are the criteria for meaningful biometry $[7,18]$. In order to correlate the bone landmarks with the skin landmarks, the thickness of the intervening soft tissue (skin, subcutaneous tissue, and muscles) should be considered.

This study's focus is on the bone landmarks of the living human that are palpated by the concerned persons (anthropologists, medical doctors, and allied health professionals). However, the surface anatomy differs from the direct observation of the bone landmarks, so that beginners become acquainted with bone landmarks referring to the learning tools: books, plastic models, dry bones, and cadavers. However, books do not provide stereoscopic features, plastic models and dry bones do not include the soft tissue covering the bone landmarks, and cadavers are not easily approachable even by medical doctors.

To compensate the existing learning tools, the computed tomographs (CTs) and magnetic resonance images (MRIs) can be utilised. These clinical images contain information not only about bone landmarks but also about the covering soft tissue. But the two-dimensional (2D) images do not permit

Address for correspondence: B.S. Chung, MD, Department of Anatomy, Ajou University School of Medicine, World cup-ro 164, Suwon 16499, Republic of Korea, tel: +82 31219 5038, fax: +82 31219 5039, e-mail: bschung@ajou.ac.kr 
beginners to promptly identify bone landmarks. In the axial CTs and MRIs, the more horizontal the skin, the more exaggerated the soft tissue thickness.

The solution is three-dimensional (3D) volume models reconstructed from serial $2 \mathrm{D}$ images. If the volume models were continuously peeled from the skin, the bone landmarks' locations and depths would be conveniently demonstrated. Rather than the CTs or MRIs, the authors have utilised the sectioned images of a cadaver from the Visible Korean because the sectioned images reveal real colour and high resolution of the human body [6]. The authors already have experience in reconstructing the volume models of certain regions or organs from the sectioned images, peeling the volume models at constant thicknesses, and utilising the composed software to browse the peeled volume models [1-4].

The purpose of this study was to help practitioners comprehend the locations and depths of the anthropological bone landmarks all over the body. For that, the sectioned images of a male cadaver were used to build a volume model, which was peeled to disclose 27 selected landmarks in the anterior, lateral, or posterior views. The captured views of the peeled volume models along with the appropriate labels and definitions of the bone landmarks were loaded into the browsing software.

\section{MATERIALS AND METHODS}

The subject was a male cadaver (age 33 years old; height $1.64 \mathrm{~m}$; weight $55 \mathrm{~kg}$ ) who had died of pneumonia. The not-embalmed subject was frozen prior to sectioning so that no artificial thickening of the soft tissue occurred, excluding its expansion by freezing. The whole body was serially sectioned to prepare the sectioned images (intervals $0.2 \mathrm{~mm}$; pixel size $0.2 \mathrm{~mm}$; colour depth 24 bits) [10].

Every five sectioned images were selected to increase the intervals to $1 \mathrm{~mm}$. The skin, bones, muscles, and other structures were already outlined to get the corresponding outlined images [14]. In both the sectioned and outlined images, the pixel size was increased to $1 \mathrm{~mm}$ as large as their intervals.

Using the sectioned images and outlined images of the skin, a volume model of the right upper limb and another volume model of the rest of the body were produced (voxel size $1 \mathrm{~mm}$ ) (Fig. 1A).

When representing the volume model, the parallel view (not the perspective view) was gained to avoid im- age distortion. For the privacy of the subject, the eyes and groin were hidden in the captured images (Fig. 1).

Using an established method [13], peeling of the volume model (thicknesses $1 \mathrm{~mm}$ ) was continuously carried out (up to $99 \mathrm{~mm}$ at most); as a result, 100 peeled models were obtained. Only the right half of the body was peeled because the intention was to compare the peeled right half to the not peeled left half (Fig. 1).

Each volume model was rotated to produce anterior, lateral, and posterior views. The volume model of the right upper limb and that of the rest were separately rotated to prevent the right upper limb from hiding the trunk in the lateral view (Fig. 1B).

A combination of the 100 peeled volume models and three directional views yielded 300 captured images. In order to achieve the software's small file size, the captured images were cropped and resized (resolution 2,000 × 1,125 pixels), and they were saved as portable network graphics (PNG) files.

These procedures were also carried out with the outlined images, and the outlines were filled with colours according to the structures. As a result, another set of 300 captured images with coded colours were obtained (Fig. 2B).

The authors decided to deal with the 27 bone landmarks that were definitely seen in the peeled volume models. Deep bone landmarks, such as the cervicale, lumbale, and trochanterion, were included even if they are not palpable on living humans. The omphalion, which is not a bone landmark, was chosen as the representative landmark in the abdomen (Table 1).

The subsequent process of labelling the individual bone landmarks was described with an example of the subnasale in the head. During peeling, the subnasale was found on the $3 \mathrm{~mm}$-peeled volume model in the anterior view, where it was labelled (Fig. 2A, Table 1). In addition, an original sectioned image to show the subnasale was selected, trimmed, and attached with the label. Moreover, the definition of the subnasale was given. This process was performed on PowerPoint 2016 for Windows (Microsoft Corp., Redmond, WA, USA) (Fig. 2A).

The browsing software had been updated to be equipped with user-friendly functions [16]. The 300 captured images of the volume models containing the information of the landmarks were arranged (Fig. 2A), as were the equivalent 300 captured images of the colour-coded volume models (Fig. 2B). 


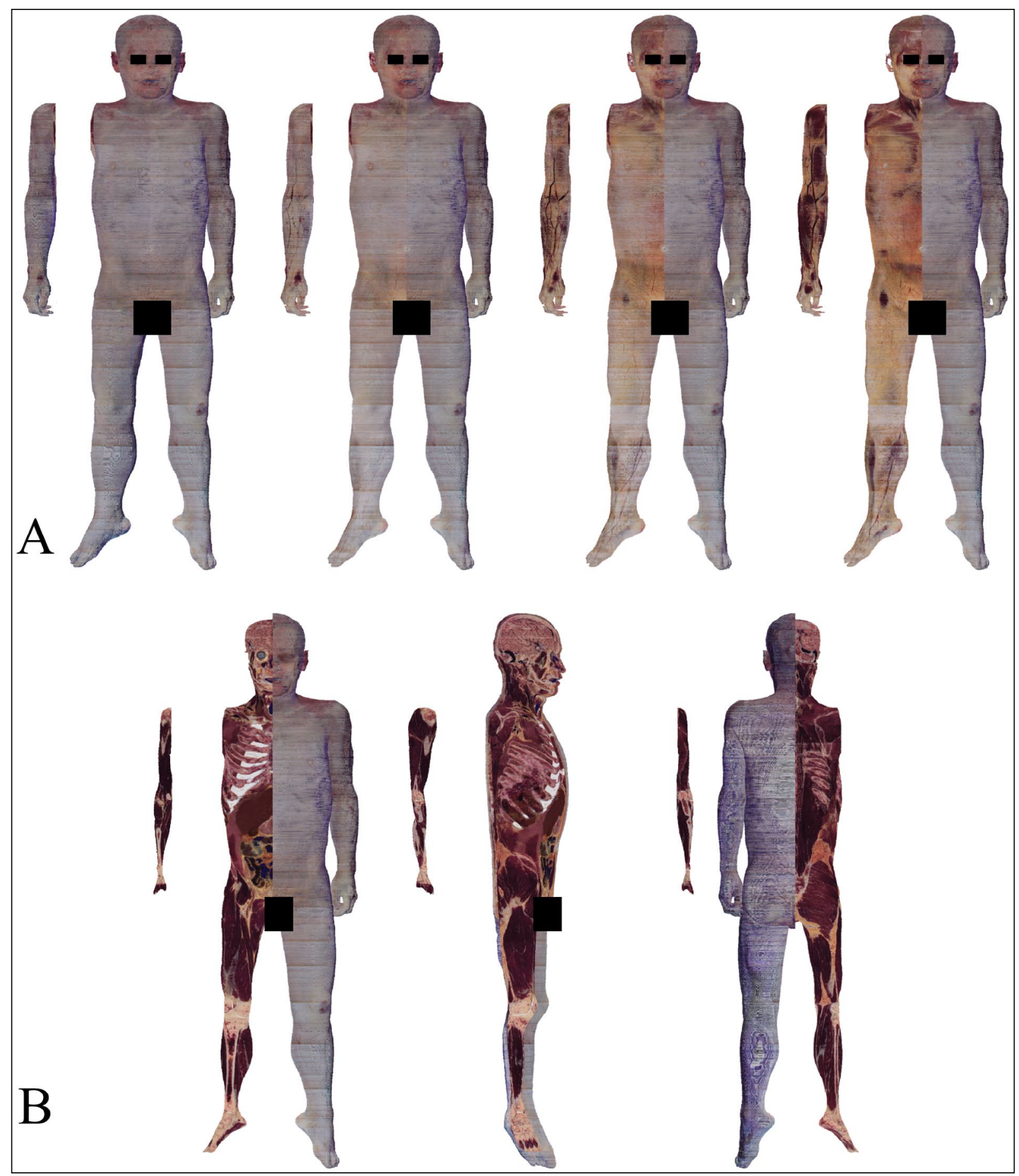

Figure 1. Volume models of the right upper limb and the rest of the body. The right half of body is gradually peeled at $1 \mathrm{~mm}$ thickness (A). The right half is peeled at $20 \mathrm{~mm}$ thickness, and two volume models are rotated (B).

\section{RESULTS}

From the Visible Korean homepage (anatomy. co.kr), the software could be downloaded without charge or registration by clicking the menu entitled "Browsing software (Male — Peeled whole body for bone landmarks) (ver. 2) (file size 237 MBytes)." After extracting the ZIP compressed file, the software was operable without installation process. The software ran off-line to show the wanted images with no time delay.

Utilising the software, the volume model was continuously peeled at $1 \mathrm{~mm}$ thicknesses with the vertical scroll bar, while the three viewing directions were selected with the horizontal buttons (Fig. 2). 


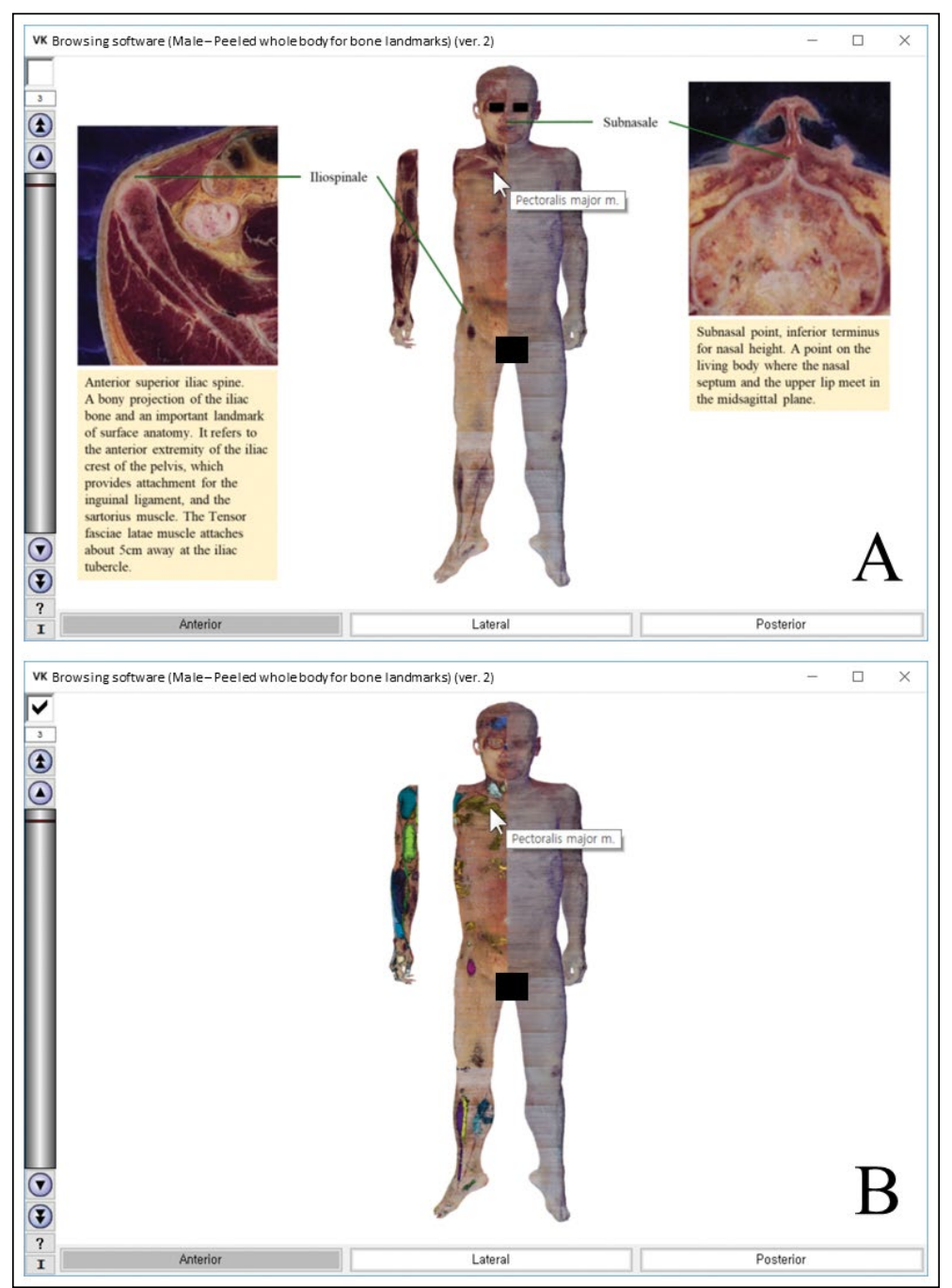

Figure 2. Browsing software to show the 3-mm-peeled volume model from the anterior view. The subnasale and iliospinale are labelled on the both volume model and sectioned images with their definitions (A). One of the outlined structures, the pectoralis major muscle, is automatically labelled on the volume model (A) and on the colour-coded volume model (B).

Table 1. Twenty-seven anthropological bone landmarks that are labelled on the peeled volume models

\begin{tabular}{|c|c|}
\hline Regions & Landmarks \\
\hline Head & $\begin{array}{l}\text { Vertex (6 mm, anterior), glabellare ( } 5 \mathrm{~mm} \text {, anterior), nasion ( } 4 \mathrm{~mm} \text {, anterior), subnasale ( } 3 \mathrm{~mm} \text {, anterior), gnathion ( } 9 \mathrm{~mm} \text {, anterior), gonion } \\
\text { (16 mm, lateral) }\end{array}$ \\
\hline Trunk & $\begin{array}{l}\text { Suprasternale ( } 5 \mathrm{~mm} \text {, anterior), mesosternale ( } 5 \mathrm{~mm} \text {, anterior), xiphale }(6 \mathrm{~mm} \text {, anterior), iliospinale ( } 3 \mathrm{~mm} \text {, anterior), symphysion } \\
\text { (14 mm, anterior), omphalion ( } 8 \mathrm{~mm} \text {, lateral), iliocristale ( } 45 \mathrm{~mm} \text {, lateral), cervicale ( } 22 \mathrm{~mm} \text {, posterior), lumbale ( } 39 \mathrm{~mm} \text {, posterior), } \\
\text { iliospinale posteiorius ( } 16 \mathrm{~mm} \text {, posterior), omphalion ( } 8 \mathrm{~mm} \text {, lateral) }\end{array}$ \\
\hline Upper limb & $\begin{array}{l}\text { Stylion ( } 7 \mathrm{~mm} \text {, anterior), dactylion ( } 2 \mathrm{~mm} \text {, anterior), acromiale }(10 \mathrm{~mm} \text {, lateral), humerale laterale }(7 \mathrm{~mm} \text {, lateral), radiale (12 mm, lateral), } \\
\text { olecranion ( } 10 \mathrm{~mm} \text {, posterior) }\end{array}$ \\
\hline Lower limb & $\begin{array}{l}\text { Patellare ( } 6 \mathrm{~mm} \text {, anterior), tibiale ( } 7 \mathrm{~mm} \text {, anterior), sphyrion ( } 4 \mathrm{~mm} \text {, anterior), trochanterion }(21 \mathrm{~mm} \text {, lateral), merion laterale (12 mm, lateral), } \\
\text { tibiale externum ( } 8 \mathrm{~mm} \text {, lateral) }\end{array}$ \\
\hline
\end{tabular}

(Depth of the landmark, suitable view to show the landmark)

In the not peeled volume model, the blue colour of the embedding agent outside the skin was also observable as an artefact (Fig. 1A) [10]. The tissue colours in the peeled volume models were consistent with those in the original sectioned images (Fig. 2A).
The software enabled users to clearly recognise the bone landmarks in the peeled volume models and sectioned images (Fig. 2A). Moreover, the images with high resolution could be zoomed in either by rolling the mouse wheel or by moving the mouse 
with its right button pressed. The zoomed in model could be shifted by moving the mouse with its left button pressed.

The depths of the bone landmarks were noticed with the peeled thickness $(\mathrm{mm})$, designated just above the vertical scroll bar like 3 (Fig. 2A). More practically, the depths could be perceived during the continuous peeling of the volume model at $1 \mathrm{~mm}$ thicknesses (Fig. 1A). For example, the same depth of the two landmarks on the sternum (suprasternale and mesosternale) could be perceived (Table 1).

A strong point of this software is that it can simultaneously display the peeled volume models (right half of body) and the not peeled volume models (left half). It facilitates comparisons of bone landmarks and skin landmarks (Figs. 1 and 2).

In the peeled volume models, the basic structures such as bones and muscles could be identified because the structures' names were shown as the tool tip text beside the mouse pointer. It was possible thanks to the corresponding colour-coded volume models. By clicking the checkbox on left upper corner, the volume model was replaced with the colour-coded volume model. This function was helpful in anatomical recognition around the bone landmarks (Fig. 2).

\section{DISCUSSION}

The present study has produced and released the browsing software to contribute to learning of the anthropological bone landmarks on living human beings. The software is gratis, fast running, and equipped with convenient tools (Fig. 2). The software also has room to be improved further.

To reveal the exact depths of the bone landmarks using the software, it is fundamentally significant to outline the skin on the sectioned images. The skin could be semiautomatically outlined because the embedding agent surrounding the subject included methylene blue; its blue colour was pretty different from the skin colour [10]. Nevertheless, in the resultant unpeeled volume model, the blue colour of the embedding agent can be irregularly seen (Fig. 1A), which means imperfect outlining. The delineation needs to be revised to ensure correct depths of the bone landmarks.

The present study involved 27 basic bone landmarks (Table 1). The remaining bone landmarks or other anatomical points (for instance, apex of heart) can be labelled in the same way. The anatomical points will serve as the reference like the colour-coded volume models (Fig. 2B).

The Visible Korean data includes the sectioned images of a females' whole body [9] and those of a male's head [11]. In a subsequent study, the former image data can be added to compare the bone landmarks between sexes. The comparison could be valuable, especially because of the different depths of the bone landmarks (in other words, different thicknesses of the soft tissue) between sexes. The latter image data can be used for identification of the more detailed bone landmarks of the head because of the higher quality of the sectioned images (intervals $0.1 \mathrm{~mm}$; pixel size $0.1 \mathrm{~mm}$; colour depth 48 bits) $[15,16]$.

It is worth to register the volume model of sectioned images to that of a patient's CTs or MRIs. Then, the patient's volume model with real colour and high resolution can be obtained [12]. With the volume model, the patient's bone landmarks can be well visualised to facilitate personalised biometry and descriptions of illness. This trial is worthy because the soft tissue covering the bone landmarks is so variable according to the obesity and so on [8].

\section{CONCLUSIONS}

By browsing the peeled volume models on the presented software, the locations and depths of the landmarks in the whole body will be efficiently realised. Then the software users can practice the various measurements of the living persons on the basis of acquired knowledge.

\section{Acknowledgements}

This research was financially supported by the Ministry of Trade, Industry and Energy (MOTIE) and Korea Institute for Advancement of Technology (KIAT) through the International Cooperative R\&D programme (Grant number: N0002249).

This work was supported by Institute for Information \& Communications Technology Promotion (IITP) grant funded by the Korea government (MSIT) (No.2017-0-018715, Development of AR-based Surgery Toolkit and Applications). Raw data of the Visible Korean Human were acquired by the assistance from the Korea Institute of Science and Technology Information.

The whole process for this study was approved by the institution review board (AJIRB-MEDMDB-18-315). 


\section{REFERENCES}

1. Chung BS, Chung MS, Shin BS, et al. Peeled and piled volume models of the kidney that show actual morphology. J Korean Med Sci. 2016; 31(10): 1514-1515, doi: 10.3346/ jkms.2016.31.10.1514, indexed in Pubmed: 27550477.

2. Chung BS, Chung MS, Shin BS, et al. Three software tools for viewing sectional planes, volume models, and surface models of a cadaver hand. J Korean Med Sci. 2018; 33(8): e64, doi: 10.3346/jkms.2018.33.e64, indexed in Pubmed: 29441756.

3. Chung B, Kwon K, Shin BS, et al. Peeled and Piled Volume Models of the Stomach Made from a Cadaver's Sectioned Images. Int J Morphol. 2016; 34(3): 939-944, doi: 10.4067/s0717-95022016000300020.

4. Chung BS, Kwon K, Shin BS, et al. Surface models and gradually peeled volume model to explore hand structures. Ann Anat. 2017; 211: 202-206, doi: 10.1016/j. aanat.2017.02.002, indexed in Pubmed: 28274804.

5. Iscan MY, Steyn M. The Human Skeleton in Forensic Medicine. Charles C Thomas Publisher. 2013.

6. Kwon K, Shin DS, Shin BS, et al. Virtual Endoscopic and Laparoscopic Exploration of Stomach Wall Based on a Cadaver's Sectioned Images. J Korean Med Sci. 2015; 30(5): 658-661, doi: 10.3346/jkms.2015.30.5.658, indexed in Pubmed: 25931800.

7. Marcolin F. Miscellaneous expertise of 3D facial landmarks in recent literature. Int J Biom. 2017; 9(4): 279, doi: 10.1504/ijbm.2017.10009329.

8. Nordander C, Willner J, Hansson GA, et al. Influence of the subcutaneous fat layer, as measured by ultrasound, skinfold calipers and BMI, on the EMG amplitude. Eur J Appl Physiol. 2003; 89(6): 514-519, doi: 10.1007/s00421-003-0819-1, indexed in Pubmed: 12712347.

9. Park H, Choi D, Park J. Improved Sectioned Images and Surface Models of the Whole Female Body. Int J Morphol. 2015; 33(4): 1323-1332, doi: 10.4067/s071795022015000400022.
10. Park JS, Chung MS, Hwang SB, et al. Visible Korean human: improved serially sectioned images of the entire body. IEEE Trans Med Imaging. 2005; 24(3): 352-360, indexed in Pubmed: 15754985.

11. Park J, Chung $M$, Shin $D$, et al. Sectioned images of the cadaver head including the brain and correspondences with ultrahigh field $7.0 \mathrm{t}$ mris. Proc IEEE. 2009; 97(12): 1988-1996, doi: 10.1109/jproc.2009.2025524.

12. Park JS, Jung YW, Lee JW, et al. Generating useful images for medical applications from the Visible Korean Human. Comput Methods Programs Biomed. 2008; 92(3): 257-266, doi: 10.1016/j.cmpb.2008.07.007, indexed in Pubmed: 18782644.

13. Shin DS, Chung MS, Shin BS, et al. Laparoscopic and endoscopic exploration of the ascending colon wall based on a cadaver sectioned images. Anat Sci Int. 2014; 89(1): 21-27, doi: 10.1007/s12565-013-0191-0, indexed in Pubmed: 23881787.

14. Shin D, Park J, Park H, et al. Outlining of the detailed structures in sectioned images from Visible Korean. Surg Radiol Anat. 2011; 34(3): 235-247, doi: 10.1007/s00276-011-0870-2.

15. Shin DS, Shim YJ, Kim BC. Sectioned images and 3D models of a cadaver head with reference to dermal filler injection. Ann Anat. 2018; 217: 34-39, doi: 10.1016/j. aanat.2018.02.001, indexed in Pubmed: 29481857.

16. Shin DS, Shim YJ, Kim BC. Sectioned images and surface models of a cadaver head with reference to botulinum neurotoxin injection. Folia Morphol. 2018; 77(3): 564-569, doi: 10.5603/FM.a2018.0005, indexed in Pubmed: 29345721.

17. Slice DE. (Ed.). Modern morphometrics in physical anthropology. Springer Science \& Business Media 2006.

18. Vezzetti E, Marcolin F, Tornincasa S, et al. Facial landmarks for forensic skull-based 3D face reconstruction: a literature review. Lecture Notes in Computer Science. 2016: 172-180, doi: 10.1007/978-3-319-40621-3_12.

19. Vij K. Textbook of Forensic Medicine \& Toxicology: Principles \& Practice-e-book. Elsevier Health Sciences 2014. 